\title{
Age-related differences in perceived asthma control in childhood: guidelines and reality
}

\author{
C.E. Kuehni, U. Frey
}

Age-related differences in perceived asthma control in childhood: guidelines and reality. C.E. Kuehni, U. Frey. C) ERS Journals Ltd 2002.

ABSTRACT: Current guidelines specify the goals of asthma treatment in children and propose a stepwise approach to achieve them. The authors sought to determine whether these goals were attained in children of different age groups in the community and to assess treatment in those with unsatisfactory asthma control.

A cross-sectional postal questionnaire survey was performed in 1998 in all members of the major Swiss parents organisation for childhood asthma.

With a response rate of $85 \%$, data from 572 Swiss-German children aged 4-16 yrs with wheeze were analysed. Asthma control was excellent in $18 \%$ of the children, satisfactory (only episodic symptoms) in $33 \%$, and unsatisfactory in $49 \%$ with disturbed sleep, restricted activities and school absences. When stratified by age, excellent or satisfactory control was attained by $66 \%$ of children aged 13-16 yrs, but only by $56 \%$, $44 \%$, and $38 \%$ of those aged $10-12,7-9$ and 4-6 yrs, respectively. Although the majority were followed-up by a doctor $(95 \%)$ and were receiving $\beta_{2}$-agonists $(82 \%)$ and inhaled corticosteroids $(68 \%)$, intensity and duration of treatment were not sufficiently matched to asthma severity. In virtually all children there was scope to improve medical treatment, preventive measures and knowledge of asthma management, with very few if any children with therapy-resistant asthma. Even in children with poor asthma control, $89 \%$ of parents were satisfied with the results of treatment.

The goals of asthma treatment were attained in one-half of the children, particularly in younger age groups. Although inhaler use was common, detailed assessment showed evidence for undertreatment, especially in the youngest age group, and insufficient adherence to preventive measures. Parental expectations of asthma control, which were lower than those outlined in guidelines, might be an important but underestimated factor in paediatric asthma management.

Eur Respir J 2002; 20: 880-889.
Paediatric Respiratory Medicine, Dept of Paediatrics, University Hospital of Bern, Inselspital, Switzerland.

Correspondence: C.E. Kuehni

Paediatric Respiratory Medicine

Dept of Paediatrics

University Hospital of Bern Inselspital CH - 3010 Bern

Switzerland

Fax: 41316324807

E-mail: claudia_kuehni@yahoo.com

Keywords: Epidemiology of childhood asthma

treatment guidelines

undertreatment

Received: July 52001

Accepted after revision: May 12002

C. Kuehni and U. Frey were supported in part by research grants from the Swiss National Science Foundation (SNF grants \# 823B - 046481 and \# $32-51974.97)$.
Asthma is the most common chronic disorder in childhood and has a large impact on quality of life of affected families and on healthcare costs [1]. Therapeutic options have improved significantly during past decades with the development of efficacious drugs and inhalation devices adapted for children and infants. Pragmatic national and international guidelines advise on diagnosis and treatment using a stepwise standardised approach [2-4]. The goals of asthma management in these guidelines are: optimal asthma control with no symptoms, undisturbed sleep, no severe exacerbations, no emergency visits, normal lung function and no limitations to daily activities such as schooling, recreation or sport.

Despite the publication of these guidelines there is still evidence for a significant degree of undertreatment in asthmatic children [5-11] and recent studies based mainly on adults suggest that the level of asthma control in the community might be far from meeting the goals $[10,11]$. The reasons for, and the extent of this undertreatment are not well explored. Treatment was usually assessed in a crude way (the proportion of children using bronchodilators or corticosteroids). A complete estimate of undertreatment, however, should assess not only absence of treatment, but also inadequate treatment in relation to asthma control. No study compared children of different age groups.

The aims of this study were to assess the degree of asthma control achieved in a large group of asthmatic children; to explore, in those with insufficient control, possible reasons, such as poor attendance rates to the family doctor, nonadherence to treatment guidelines, poor compliance, parental expectations, and the presence of very severe, therapy-resistant disease; to investigate whether asthma control and treatment were associated with sociodemographic measures, such as age, sex and social class.

\section{Methods}

\section{Study design and population}

A cross-sectional postal survey was carried out of the Swiss Association of Parents of Asthmatic and 
Allergic Children (SEAAK). Two-thirds of its 1,186 members have asthmatic children. Compared to the general population, this group has a higher than average social class distribution and a larger proportion of children in specialist care. In October 1998, all families were asked to fill in a standardised questionnaire on sociodemographic factors, indoor environment, family history of atopic disease and knowledge of asthma management. In addition, the families were asked to complete a questionnaire on asthma symptoms and treatment for each asthmatic child. Nonresponders were sent a second set of questionnaires 6 weeks later. The study was approved by the Ethics Committee of the University Children's Hospital of Bern, Bern, Switzerland. Parents were encouraged to return the questionnaires blank if they did not wish to participate.

\section{Questionnaires}

To facilitate comparisons with national and international data, prevalence and severity of respiratory symptoms were assessed using the International Study of Asthma and Allergies in Childhood (ISAAC) core questions [12] supplemented by validated questions from other published asthma questionnaires [7, 13-15]. Asthma treatment was assessed in detail (substance, dosage, duration, medical follow-up). In addition, questions were included on treatment adherence (under- or overuse of inhalers compared to prescriptions, frequency of forgetting inhalations, reasons for under use of inhalers), problems in relation to therapy, parent-assessed asthma severity (severe, moderate, mild, low), perceived success of treatment (excellent, satisfactory, partly satisfactory, unsatisfactory), and a few questions on asthma management knowledge. In total, the questionnaires contained 71 questions, many with multiple items, and required 10-15 min to complete the core family section and a further 10-15 min for every asthmatic child.

\section{Definitions}

Asthma severity was assessed with a validated score, based on the occurrence and frequency of six respiratory symptoms during the past 12 months [13]. Control of asthma, as defined in asthma guidelines [2, 4], was categorised into four groups: 1) good control (no limitations on play, sport and family activities, undisturbed sleep, no severe attack, no school absence); 2) satisfactory control (limitations on activities or disturbed sleep episodically); 3) unsatisfactory (limitations on activities at least monthly or severe attack/school absence during the past year); and 4) poor (limitations on activities or disturbed sleep at least weekly). Medical treatment was categorised into five steps following the guidelines of the British Thoracic Society (BTS) [3]. Regular treatment was defined as uninterrupted inhaler use for a minimum of 3 months during the past year, episodic treatment as treatment only during attacks or for $<3$ months at a time.

\section{Analysis}

All questionnaires were double-entered onto a personal computer using Epi Info Software, Version 6.04b (Centre for Disease Control and Prevention, Atlanta, GA, USA), subsequent analyses were performed using STATA, version 6.0 for Windows (STATA Corporation, TX, USA). Standard errors were adjusted for clusters (some families had more than one child) by using survey estimation methods and results given with $95 \%$ confidence intervals (95\% CI). Unconditional logistic regression, multinominal (politomous) logistic regression and ordered logistic regression were used to adjust for confounding factors with results expressed as odds ratios (OR). Pearson's Chi-squared tests with second-order Rao and Scott correction were used to test for statistical significance when comparing proportions, and likelihood ratio tests for logistic regressions.

\section{Results}

\section{Response rate}

Completed questionnaires were returned by 685 out of 1,186 families for 772 children. As only two-thirds of the members had asthmatic children aged $\leqslant 16$ yrs this corresponded to a relevant response rate of $\sim 85 \%$ of all children with asthma in this sample. The following groups were excluded from the analysis to minimise language problems and to allow the application of homogenous diagnostic criteria and therapeutic guidelines: first language not Swiss-German $(n=45)$, nationality not Swiss $(\mathrm{n}=9)$, children aged $<4$ yrs $(n=65)$ or $>16$ yrs $(n=62)$, and children who had never suffered from wheezing $(n=19)$. This left 572 children's questionnaires from 464 families. A total $87 \%$ had been completed by the mother, $5 \%$ by the father, and $8 \%$ by both parents. The proportion of children participating in completing the questionnaires increased from $2 \%$ in those aged $4-6$ yrs, to $6 \%, 14 \%$ and $29 \%$ in those aged 7-9, 10-12 and 13-16 yrs, respectively. Data quality was good with 1-3\% missing answers in questions on symptoms and $10 \%$ missing answers in questions on therapy. The proportion of missing data was not associated with age except for one question (forgetting inhalations). Twothirds of the respondents were males, and asthma severity was comparable to general population samples of wheezing children [13] (table 1).

\section{Asthma control}

In total, 522 children $(91 \%)$ reported wheeze within the last 12 months, $50(9 \%)$ had wheezed before but not within the past year. A significant proportion of the children suffered from persistent symptoms and limitations on activities during the past 12 months, or reported emergency visits to their doctor's office (table 2). With the exception of limitation of sporting activities, all complaints were significantly more common in younger children. Overall, control of asthma 
Table 1.-Descriptive characteristics of the participating children

\begin{tabular}{lcc}
\hline & $\mathrm{n}$ & $\%$ \\
\hline Age yrs & & \\
$4-6$ & 113 & 20 \\
$7-9$ & 191 & 33 \\
$10-12$ & 146 & 26 \\
$13-16$ & 122 & 21 \\
Sex & & \\
Male & 365 & 64 \\
Female & 207 & 36 \\
Father's professional education & 135 & 24 \\
Vocational training <4 yrs & 130 & 23 \\
Vocational training $\geqslant 4$ yrs & 190 & 33 \\
Teachers college, Engineering school & 105 & 18 \\
University & & \\
Family history & 236 & 41 \\
Asthma (one or both parents) & 223 & 39 \\
Inhaler treatment (one or both & & \\
$\quad$ parents) past 12 months & & \\
Asthma severity score & \\
Low & 288 & 62 \\
Mild & 106 & 23 \\
Moderate & 64 & 14 \\
High & 8 & 2 \\
\hline
\end{tabular}

\#: based on the occurrence and frequency of six respiratory symptoms during the past 12 months [13]; 106 children could not be scored because of "don't know" or missing answers in at least one question.

was good in $18 \%$, satisfactory in $33 \%$, unsatisfactory in $28 \%$ and poor in $21 \%$ of the children. Excellent or satisfactory control was attained by $38 \%$ of children aged $4-6$ yrs, but by $44 \%, 56 \%$ and $66 \%$ of children aged $7-9,10-12$ and $13-16$ yrs, respectively $(\mathrm{p}=0.0001$, fig. 1).

Even after adjusting for age-dependent differences in asthma treatment (BTS step, antibiotics; see below) in an ordered logistic regression, poor asthma control remained significantly associated with young age $(\mathrm{p}<0.0001)$ and with poor asthma management knowledge $(p=0.004)$, but not with parental education, parental asthma, sex of the child, preventive measures or indoor environment.

\section{Asthma management}

Medical treatment. During the past 12 months, 471 children $(82 \%)$ used $\beta_{2}$-agonists and $387(68 \%)$ inhaled corticosteroids (ICS). However, most children took inhaled steroids for short periods only: $33 \%$ (128 out of $387)$ for $<3$ months $\cdot y^{-1}$. Regular inhaled steroids were generally used (205 out of $259,79 \%$ ) in combination with regular $\beta_{2}$-agonists. Long-acting $\beta_{2}$-agonists were reported by 161 children $(28 \%)$, usually $(118,21 \%)$ combined with ICS as long-term preventive treatment. Fifty children $(9 \%)$ had only long-acting (instead of short-acting) $\beta_{2}$-agonists for acute attacks. Disodium cromoglycate was used by 87 children $(15 \%)$, of whom 60 had also topical corticosteroids.

All but one of the children with unsatisfactory or poor asthma control $(\mathrm{n}=279)$ were followed-up for asthma (in $50 \%$ by a specialist), and $52 \%$ of those aged
$>6$ yrs had a lung function test performed within the past 12 months (table 3). Although children with unsatisfactory control had significantly higher levels of medical treatment compared to well-controlled children, there was still ample opportunity for increasing intensity (BTS treatment step) and duration of treatment (table 3 ); only 15 children with unsatisfactory control had been on step 4 for the past 12 months. None had regular oral steroids. The Swiss guidelines propose an extension of treatment with ICS by 4 weeks with every additional asthma attack. This implies continuous daily treatment for children with 12 attacks yearly. However, only nine out of 36 children reporting $>12$ attacks $(25 \%)$ had used ICS daily for the last 12 months. Long-acting $\beta_{2}$-agonists were used only by $54 \%$ (95\% CI $34-73)$ of the children with frequent (weekly or more often) limitations on sporting activities and by $32 \%$ (95\% CI 16-49) of children with frequently disturbed sleep due to wheeze.

There was little evidence for overtreatment: 49 children with good or satisfactory asthma control were on step 3 or 4 of the BTS guidelines; however, only 12 of them had $>800 \mu \mathrm{g}$ budesonide (or $>500 \mu \mathrm{g}$ fluticasone) daily for a duration of 6 months or longer during the past year.

In summary, these data suggest that even though children with unsatisfactory asthma control received more intensive medical treatment than well-controlled children, treatment intensity was still insufficient.

Preventive measures. While dust-mite-proof bed covers were more common in children with unsatisfactory control, avoidance of tobacco smoke and pets did not differ between groups (table 4). Of the 210 children reporting pets as triggers of their asthma symptoms, $36 \%(95 \%$ CI 29-43) nevertheless kept pets in their home. Of the 201 children reporting house dust as an asthma trigger, 76\% (69-83\%) used a dust miteproof mattress cover, $41 \%$ (34 $49 \%$ ) had a cover on all bedding (mattress, pillow and duvet), and $67 \%$ (60-74\%) had a carpet-free bedroom. Asthma management knowledge was unsatisfactory in both groups (table 4). In total, 28\% of the children using inhalers reported using them less often than prescribed; either because of forgetfulness or deliberately (mainly for fear of side-effects). Adherence did not differ between wellcontrolled and poorly controlled children (table 4).

Age-related differences in asthma management. A similar proportion of children $(42 \%)$ were followedup by specialists in each age group. Children aged 4-6 yrs were more likely to have had an allergy test but less likely to have had a lung function test within the past year compared to older children (table 5). Treatment intensity (BTS step) differed significantly by age group (table 5); even after adjusting for parentreported asthma severity and asthma control in an ordered logistic regression, treatment intensity was highest in children aged 10-12 yrs, followed by those aged 7-9, 13-16 and 4-6 yrs. Treatment intensity in the youngest children was significantly lower compared to all other age groups $(\mathrm{p}=0.001$ compared to children aged $10-12, \mathrm{p}<0.01$ compared to the other two age groups). In a second approach, using a multinominal 
Table 2. - Control of asthma: prevalence of asthma symptoms, limitations on activities and emergency healthcare utilisation during the past 12 months, in entire sample and stratified by age

\begin{tabular}{|c|c|c|c|c|c|c|c|c|}
\hline \multirow[t]{2}{*}{ Symptoms (last 12 months) } & \multicolumn{3}{|c|}{ Entire sample } & \multicolumn{4}{|c|}{ Age yrs } & \multirow[t]{2}{*}{ p-value } \\
\hline & $\mathrm{n}$ & $\%$ & $95 \% \mathrm{CI}$ & $4-6$ & $7-9$ & $10-12$ & $13-16$ & \\
\hline \multicolumn{9}{|l|}{ Asthma attacks $\#$} \\
\hline$>12$ & 36 & 6.5 & $4.4-8.5$ & 3.6 & 8.1 & 4.9 & 8.5 & \multirow[t]{3}{*}{$<0.05$} \\
\hline $4-12$ & 147 & 26.3 & $22.5-30.2$ & 35.1 & 30.3 & 22.2 & 16.9 & \\
\hline $1-3$ & 184 & 33.0 & $28.9-37.0$ & 35.1 & 33.0 & 32.6 & 31.4 & \\
\hline \multicolumn{9}{|l|}{ Severe attack (with speech limitation) ${ }^{\#}$} \\
\hline Yes & 88 & 15.7 & $12.5-18.8$ & 23.9 & 17.2 & 13.9 & 8.2 & $<0.01$ \\
\hline \multicolumn{9}{|l|}{ Woken up at night with cough or wheeze } \\
\hline $1-3$ nights $\cdot$ week ${ }^{-1}$ or most nights & 25 & 4.6 & $2.8-6.4$ & 7.4 & 6.0 & 2.9 & 1.8 & \multirow[t]{3}{*}{$<0.001$} \\
\hline$<1$ night $\cdot$ week $^{-1}$ & 40 & 7.4 & $5.2-9.6$ & 13.0 & 8.2 & 4.3 & 4.5 & \\
\hline Only with episodes & 284 & 52.4 & $47.9-56.8$ & 62.0 & 57.9 & 50.7 & 36.0 & \\
\hline \multicolumn{9}{|l|}{ Wheeze first thing in the morning } \\
\hline 1-3 mornings $\cdot$ week $^{-1}$ & 13 & 2.4 & $1.0-3.8$ & 2.9 & 1.7 & 2.9 & 2.7 & \multirow[t]{3}{*}{$<0.05$} \\
\hline$<1$ morning $\cdot$ week $^{-1}$ & 22 & 4.1 & $2.4-5.8$ & 5.7 & 5.6 & 0.0 & 5.3 & \\
\hline Only with episodes & 239 & 44.7 & $40.3-49.0$ & 50.5 & 46.7 & 48.2 & 31.9 & \\
\hline \multicolumn{9}{|l|}{ Limitation of activities at home/playing } \\
\hline Daily or weekly & 25 & 4.7 & $2.8-6.6$ & 5.9 & 6.2 & 2.9 & 3.4 & \multirow[t]{3}{*}{$<0.01$} \\
\hline Monthly & 40 & 7.5 & $5.3-9.7$ & 9.8 & 10.2 & 6.5 & 2.6 & \\
\hline Less often & 178 & 33.3 & $29.1-37.6$ & 44.1 & 33.3 & 31.2 & 26.5 & \\
\hline \multicolumn{9}{|l|}{ Limitation of sporting activities } \\
\hline Daily or weekly & 36 & 6.8 & $4.5-9.1$ & 6.0 & 6.8 & 4.3 & 10.6 & \\
\hline Monthly & 46 & 8.7 & $6.2-11.1$ & 11.0 & 7.9 & 9.3 & 7.1 & \\
\hline Less often & 225 & 42.5 & $38.1-46.9$ & 41.0 & 44.1 & 47.1 & 35.4 & \\
\hline \multicolumn{9}{|l|}{ Family activities disturbed $^{+}$} \\
\hline Very much or much & 13 & 2.3 & $1.0-3.7$ & 5.6 & 0.5 & 1.4 & 3.3 & \multirow[t]{3}{*}{$<0.001$} \\
\hline Moderately & 88 & 15.9 & $12.6-19.2$ & 22.4 & 22.4 & 9.8 & 7.4 & \\
\hline A little & 177 & 31.9 & $27.8-36.1$ & 42.1 & 35.0 & 31.5 & 19.0 & \\
\hline \multicolumn{9}{|l|}{ School absences due to asthma ${ }^{\S}$} \\
\hline$<1$ week & 95 & 17.3 & $14.1-20.6$ & 21.7 & 22.5 & 14.6 & 9.0 & \multirow[t]{3}{*}{$<0.01$} \\
\hline $1-2$ weeks & 59 & 10.7 & $8.0-13.5$ & 13.0 & 12.0 & 13.2 & 4.1 & \\
\hline$>2$ weeks & 15 & 2.7 & $1.3-4.2$ & 4.3 & 3.1 & 2.8 & 0.8 & \\
\hline \multicolumn{9}{|l|}{ Emergency healthcare utilisation } \\
\hline Emergency visit to doctor & 85 & 16.4 & $13.0-19.9$ & 27.0 & 21.1 & 11.5 & 5.4 & \multirow{3}{*}{$\begin{array}{l}<0.001 \\
<0.01\end{array}$} \\
\hline Hospital emergency dept & 15 & 3.0 & $1.4-4.6$ & 6.2 & 5.4 & 0.0 & 0.0 & \\
\hline Hospitalisation for asthma & 7 & 1.4 & $0.2-2.6$ & 3.2 & 2.4 & 0.0 & 0.0 & \\
\hline
\end{tabular}

Data are presented as \% unless otherwise stated. CI: confidence interval. As children with missing answers or "don't know" were excluded from the analysis, $n$ was slightly lower than 572 in most questions. Source of questions: ${ }^{\#}:[12] ;{ }^{\uparrow}:[13] ;{ }^{+}:[15] .{ }^{\S}$ : the denominator was all children who go to school or kindergarten $(n=504)$. All symptoms (except limitation of sporting activities) were significantly more common in younger children.

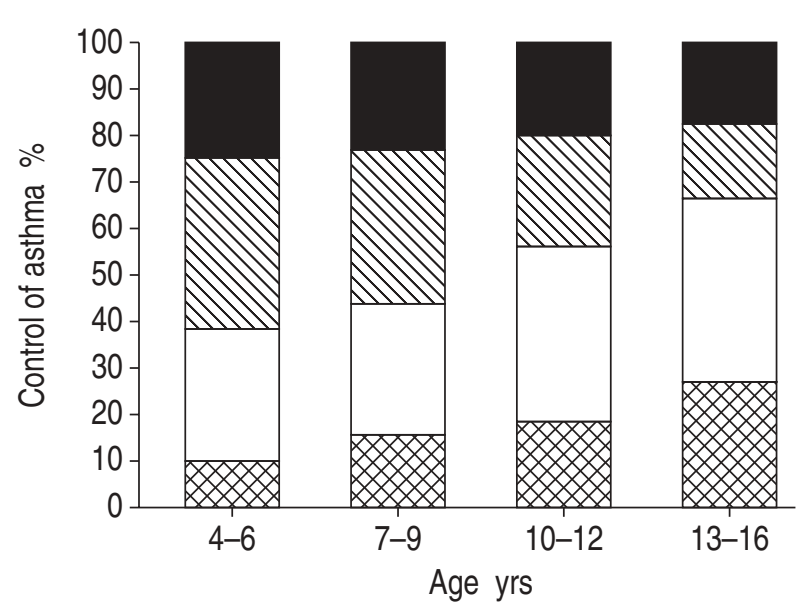

Fig. 1.-Control of asthma in children of different age groups. good control; $\square$ : satisfactory control; $\mathbb{\mathbb { Q }}$ : unsatisfactory control; : poor control. Control of asthma was significantly better in older children $(\mathrm{p}=0.0001)$ logistic regression model with step 2 as standard treatment, it was shown that 4-6-yr olds were more likely to be on step 0 (OR 2.2, p=0.01) and less likely to be on step 3 or 4 of the BTS guidelines (OR 0.28 , $\mathrm{p}<0.001)$ compared to older children, adjusting for both parent-reported asthma severity and (more objective) symptom-based asthma control. Conversely, adolescents (aged 13-16 yrs) were more often on step 1 (short-acting $\beta_{2}$-agonists as needed) compared to younger children (OR 4.3, $\mathrm{p}=0.003$ ).

Antibiotics were more commonly used in younger children $(\mathrm{p}<0.01)$; this remained significant after adjusting for asthma control $(\mathrm{p}=0.03)$ but became nonsignificant after adjusting for frequency of colds. In contrast to age, other sociodemographic factors such as parental social class, parental asthma or sex of the child were not associated with treatment intensity. Although younger children were usually dependent on parental help for inhalation therapy (table 5) and needed more time (a median of 10,5, 5, and $3 \mathrm{~min} \cdot \mathrm{day}^{-1}$ for children aged $4-6,7-9,10-12$ and 
Table 3. - Medical treatment (past 12 months prior to questionnaire) in the children according to control of asthma

\begin{tabular}{|c|c|c|c|c|}
\hline & \multicolumn{4}{|c|}{ Control of asthma } \\
\hline & \multicolumn{2}{|c|}{ Good or satisfactory } & \multicolumn{2}{|c|}{ Unsatisfactory or poor } \\
\hline & $\mathrm{n}(\%)$ & $95 \% \mathrm{CI}$ & $\mathrm{n}(\%)$ & $95 \% \mathrm{CI}$ \\
\hline \multicolumn{5}{|l|}{ Medical follow-up } \\
\hline None & $24(8)$ & $5-12$ & $2(1)$ & $0-2^{f f}$ \\
\hline Primary care only ${ }^{\#}$ & $169(58)$ & $52-64$ & $139(49)$ & $43-55$ \\
\hline Specialist care & $97(33)$ & $28-39$ & $141(50)$ & $44-56$ \\
\hline \multicolumn{5}{|l|}{ Lung function measurements ${ }^{+}$} \\
\hline Within last 12 months & $85(36)$ & $30-43$ & $106(52)$ & $45-59^{f}$ \\
\hline Earlier, but not last 12 months & $88(38)$ & $31-44$ & $57(28)$ & $22-34$ \\
\hline Never & $60(26)$ & $20-32$ & $42(20)$ & $15-26$ \\
\hline \multicolumn{5}{|l|}{ BTS guidelines treatment $s t e p^{\S}$} \\
\hline No treatment & $72(25)$ & $20-30$ & $18(6)$ & $4-9^{f f}$ \\
\hline Step 1 & $41(14)$ & $10-19$ & $19(7)$ & $4-10$ \\
\hline Step 2 & $125(44)$ & $38-50$ & $156(56)$ & $50-62$ \\
\hline Step 3 & $34(12)$ & $8-16$ & $61(22)$ & $17-27$ \\
\hline Step 4 & $15(5)$ & $2-8$ & $25(9)$ & $6-12$ \\
\hline \multicolumn{5}{|l|}{ Inhaled corticosteroids } \\
\hline No corticosteroids & $129(46)$ & $40-52$ & $51(19)$ & $14-24^{f f}$ \\
\hline$<3$ months & $61(22)$ & $17-27$ & $66(25)$ & $19-30$ \\
\hline $3-5$ months & $17(6)$ & 3-9 & $46(17)$ & $12-22$ \\
\hline $6-11$ months & $22(8)$ & $5-11$ & $30(11)$ & $7-15$ \\
\hline 12 months & $50(18)$ & $13-23$ & $73(27)$ & $22-33$ \\
\hline \multicolumn{5}{|l|}{ Additional treatment for attacks } \\
\hline Antibiotics & $13(4)$ & $2-7$ & $58(21)$ & $16-26^{f f}$ \\
\hline Steroid tablets & $7(2)$ & $0-4$ & $47(17)$ & $12-21^{f f}$ \\
\hline Bronchodilator syrups or drops & $7(2)$ & $0-4$ & $13(5)$ & $2-7$ \\
\hline
\end{tabular}

CI: confidence interval; BTS: British Thoracic Society; step 1: short-acting $\beta_{2}$-agonist as needed; step 2: short-acting $\beta_{2^{-}}$ agonist plus low-dose inhaled corticosteroid or cromoglycate regularly; step 3 : short-acting $\beta_{2}$-agonist plus either high-dose inhaled corticosteroid or long-acting $\beta_{2}$-agonist and low-dose inhaled corticosteroid regularly; step 4: long-acting $\beta_{2}$-agonist plus high-dose inhaled corticosteroid regularly; low-dose: up to $400 \mu \mathrm{g}$ budesonide or $250 \mu \mathrm{g}$ fluticasone daily. ${ }^{\#}$ : general paediatrician or general practioner; ${ }^{\uparrow}$ : pulmonologist or allergologist; ${ }^{+}$: spirometry or plethysmography, the denominator was all children aged 7-16 yrs ( $\mathrm{n}=459)$; : treatment steps recommended by the BTS [3] and adapted. Differences between groups (control of asthma) were statistically significant for all questions. ${ }^{f}: \mathrm{p}=0.006 ;{ }^{f f}: \mathrm{p}<0.0001 . \mathrm{n}=287$ for good or satisfactory and $\mathrm{n}=279$ for unsatisfactory or poor.

Table 4.-Indoor environment, asthma management knowledge and reported compliance according to control of asthma

\begin{tabular}{|c|c|c|c|c|}
\hline & \multicolumn{4}{|c|}{ Control of asthma } \\
\hline & \multicolumn{2}{|c|}{ Good or satisfactory } & \multicolumn{2}{|c|}{ Unsatisfactory or poor } \\
\hline & $\mathrm{n}(\%)$ & $95 \% \mathrm{CI}$ & n $(\%)$ & $95 \% \mathrm{CI}$ \\
\hline \multicolumn{5}{|l|}{ Indoor environment } \\
\hline At least one smoker in household & $61(21)$ & $16-26$ & $68(24)$ & $19-29$ \\
\hline Pet & $112(39)$ & $33-46$ & $117(42)$ & $36-48$ \\
\hline Cat & 54 (19) & $14-24$ & 53 (19) & $14-24$ \\
\hline Mattress cover & $116(42)$ & $35-48$ & $149(54)$ & $47-60 * *$ \\
\hline Cover on mattress, pillow and duvet & $57(20)$ & $15-25$ & $76(27)$ & $21-32 *$ \\
\hline Smooth floor (no carpet) & $151(52)$ & $46-58$ & $167(59)$ & $53-65$ \\
\hline \multicolumn{5}{|l|}{ Asthma management knowledge } \\
\hline Drug effects & $117(40)$ & $34-47$ & $143(51)$ & $44-57$ \\
\hline Advantage of inhalation chamber & $235(81)$ & $76-86$ & $247(88)$ & $84-92$ \\
\hline Recommended indoor air humidity & $171(59)$ & $53-65$ & $157(56)$ & $49-62$ \\
\hline \multicolumn{5}{|l|}{ Compliance with medication } \\
\hline Inhalers forgotten at least weekly & $46(21)$ & $15-27$ & $51(19)$ & $14-25$ \\
\hline Deliberate underuse of inhalers & 41 (19) & $13-25$ & $46(17)$ & $13-22$ \\
\hline Total noncompliance & $62(28)$ & $22-35$ & $74(28)$ & $22-34$ \\
\hline
\end{tabular}

CI: confidence interval. ${ }^{*}$ : broncodilator versus steroids; ${ }^{\bullet}$ : denominator, all children reporting any inhaled treatment in the past 12 months $(n=482){ }^{*}: \mathrm{p}<0.05 . * *: p<0.01 . n=287$ good or satisfactory, $n=279$ unsatisfactory or poor. 
Table 5. - Medical treatment (past 12 months prior to questionnaire) according to age of the children

\begin{tabular}{|c|c|c|c|c|c|c|c|c|}
\hline & \multicolumn{3}{|c|}{ Entire sample } & \multicolumn{4}{|c|}{ Age yrs } & \multirow[t]{2}{*}{$\mathrm{p}$-value } \\
\hline & $\mathrm{n}$ & $\%$ & $95 \% \mathrm{CI}$ & $4-6$ & $7-9$ & $10-12$ & $13-16$ & \\
\hline \multicolumn{9}{|l|}{ BTS guidelines treatment step $p^{\#}$} \\
\hline No treatment & 90 & 15.9 & $12.7-19.1$ & 23.2 & 14.9 & 9.0 & 18.9 & \multirow[t]{4}{*}{$<0.001$} \\
\hline Step 1 & 60 & 10.6 & $7.9-13.3$ & 6.3 & 7.5 & 9.7 & 20.5 & \\
\hline Step 2 & 281 & 49.7 & $45.3-54.0$ & 59.8 & 53.2 & 48.6 & 36.1 & \\
\hline Step 3 or 4 & 135 & 23.9 & $20.2-27.6$ & 10.7 & 24.5 & 32.6 & 24.6 & \\
\hline \multicolumn{9}{|l|}{ Additional treatment for attacks } \\
\hline Antibiotics & 71 & 12.4 & $9.4-15.4$ & 19.5 & 14.1 & 8.9 & 7.4 & \multirow{3}{*}{$\begin{array}{c}<0.01^{+} \\
0.01^{+}\end{array}$} \\
\hline Steroid tablets & 54 & 9.4 & $6.9-12.0$ & 15.9 & 10.0 & 6.2 & 6.6 & \\
\hline \multicolumn{8}{|l|}{ Lung function measurements } & \\
\hline Within last 12 months & 212 & 39.2 & $34.8-43.6$ & 20.4 & 46.9 & 48.2 & 33.1 & \multirow[t]{2}{*}{$<0.0001$} \\
\hline Earlier, but not last 12 months & 153 & 28.3 & $24.2-32.4$ & 7.8 & 22.9 & 31.9 & 50.0 & \\
\hline \multicolumn{9}{|l|}{ Allergy tests } \\
\hline Within last 12 months & 149 & 27.5 & $23.5-31.5$ & 35.5 & 33.2 & 24.1 & 15.0 & \multirow[t]{2}{*}{$<0.001$} \\
\hline Earlier, but not last 12 months & 336 & 62.0 & $57.6-66.3$ & 43.0 & 57.5 & 70.9 & 76.1 & \\
\hline \multicolumn{9}{|l|}{ Inhalation therapy } \\
\hline Needs parental help & 262 & 51.9 & $47.3-56.5$ & 93.4 & 64.7 & 35.8 & 17.3 & $<0.0001$ \\
\hline Problems with inhalations & 57 & 11.5 & $8.4-14.5$ & 12.0 & 11.3 & 12.7 & 9.6 & 0.90 \\
\hline Treatment unsuccessful & 55 & 10.9 & $7.7-14.0$ & 17.2 & 12.3 & 9.1 & 5.5 & $0.01^{+}$ \\
\hline
\end{tabular}

BTS: British Thoracic Society; CI: confidence interval; step 1: short-acting $\beta_{2}$-agonist as needed; step 2: short-acting $\beta_{2}$-agonist plus low-dose inhaled corticosteroid or cromoglycate regularly; step 3: short-acting $\beta_{2}$-agonist plus either high-dose inhaled corticosteroid or long-acting $\beta_{2}$-agonist and low-dose inhaled corticosteroid regularly; step 4: long-acting $\beta_{2}$-agonist plus high-dose inhaled corticosteroid regularly; low-dose: up to $400 \mu \mathrm{g}$ budesonide or $250 \mu \mathrm{g}$ fluticasone daily. \#: treatment steps recommended by the BTS [3] and adapted; " spirometry or plethysmography, the denominator was all children aged 7-16 yrs $(\mathrm{n}=459) ;{ }^{+}$: Chi-squared test for trend.

13-16 yrs, respectively, $\mathrm{p}=0.0001$ ), they did not report problems with inhalations more frequently. Also, uptake of preventive measures, asthma management knowledge and reported adherence with medical treatment did not differ significantly with age or sex of the child.

\section{Parental satisfaction with asthma control}

Even in children whose asthma control was, according to guidelines, unsatisfactory or poor, most parents were satisfied with the results of medical treatment,

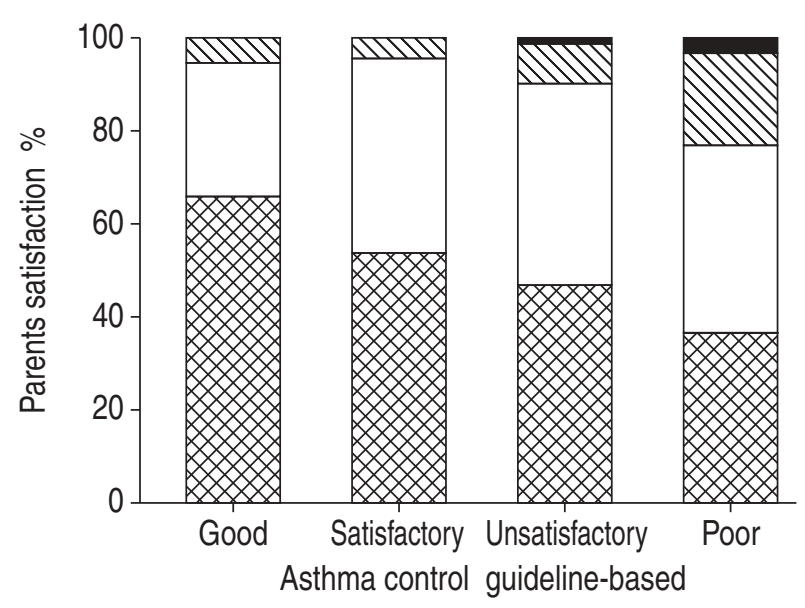

Fig. 2.-Parents' satisfaction with success of asthma treatment, compared to overall asthma control (based on goals set in

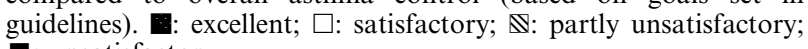
: unsatisfactory. which they described as excellent or satisfactory (fig. 2) Using multivariate logistic regression, subjective parental dissatisfaction with asthma control remained associated with objectively assessed poor asthma control, but was also independently predicted by large family size, higher maternal education, low adherence with treatment and problems with inhalation therapy (table 6).

\section{Discussion}

While several national and international guidelines on management of childhood asthma have been published, little is known regarding the achievement of desired treatment goals. A survey was used of the national Swiss parents organisation for asthmatic children where, in contrast to random population samples, almost all children are diagnosed and under regular follow-up to assess the level of asthma control attained and to compare the treatment with current guidelines.

The main findings were that the goals of asthma treatment specified in guidelines were met in only $50 \%$ of the children. Although asthma treatment was better than in published surveys of random population samples, treatment intensity (BTS step) and duration were still insufficiently matched to the current level of symptoms, and important gaps in asthma management knowledge and implementation of preventive measures existed. Parental expectations of asthma control were in many cases less than those outlined in guidelines. Control and treatment of asthma in this group were not associated with sex or social class, but a significant association was found 
Table 6. - Predictors of parent's dissatisfaction with asthma control: odds ratios (OR), comparing children whose parents reported treatment results as "unsatisfactory or poor" compared to those reporting them as "optimal or satisfactory"

\begin{tabular}{|c|c|c|c|}
\hline & OR & $95 \% \mathrm{CI}$ & p-value $e^{\#}$ \\
\hline \multicolumn{4}{|l|}{$\begin{array}{l}\text { Asthma control (assessed } \\
\text { objectively, based on } \\
\text { guidelines) }\end{array}$} \\
\hline Optimal & 1 & & \\
\hline Satisfactory & 1.25 & $0.22-6.93$ & \\
\hline Partly satisfactory & 3.00 & $0.53-16.9$ & \\
\hline Unsatisfactory & 8.19 & $1.56-42.8$ & 0.0002 \\
\hline \multicolumn{4}{|l|}{ Family size } \\
\hline 1 or 2 children & 1 & & \\
\hline 3 children & 1.87 & $0.68-5.16$ & \\
\hline 4 children & 4.58 & $1.57-13.4$ & 0.020 \\
\hline \multicolumn{4}{|l|}{$\begin{array}{l}\text { Mother's professional } \\
\text { education }\end{array}$} \\
\hline$<4$ yrs & 1 & & \\
\hline$\geqslant 4 \mathrm{yrs}$ & 3.15 & $1.36-7.28$ & $<0.0001$ \\
\hline Age of the child per year & 0.91 & $0.82-1.01$ & 0.085 \\
\hline \multicolumn{4}{|l|}{ Adherence with treatment } \\
\hline Good & 1 & & \\
\hline Low & 3.72 & $1.62-8.55$ & 0.0011 \\
\hline \multicolumn{4}{|l|}{$\begin{array}{l}\text { Having problems with } \\
\text { inhalations }\end{array}$} \\
\hline No & 1 & & \\
\hline Yes & 4.35 & $1.65-11.5$ & 0.0002 \\
\hline
\end{tabular}

Multivariate logistic regression, adjusting for all listed factors simultaneously. CI: confidence interval. ${ }^{\#}$ : likelihood ratio test.

with age. Asthma control was much poorer in younger children, even adjusting for age-dependent differences in treatment.

This is the first survey which provides information on asthma control in children of different age categories, confirming recent studies based mainly on adults, which suggested that the level of asthma control in Europe and the USA might fall short of the goals $[10,11,16,17]$. Compared to a large populationbased survey, which included adults and children with a doctors diagnosis of asthma from seven European countries, asthma control was significantly better in the present population, even taking into account a possibly different age distribution: weekly sleep disturbance was reported by $4.6 \%$ in this study versus $28 \%$ of children in the European study, school absence by $32 \%$ versus $43 \%$, unscheduled emergency visits by $16 \%$ versus $36 \%$ and visits in a hospital emergency department by $3 \%$ versus $18 \%$ [10]. Other surveys in adults [11, 16, 17] and children [18] also reported higher rates of sleep disturbance, restrictions on activities and emergency care utilisation. These studies were performed in general population samples, therefore a significant proportion of the asthmatics might not be have been diagnosed as such or even have presented to a doctor. The present study of a parents organisation includes only children who are diagnosed and currently followed-up and have highly motivated parents. Therefore, the finding, that $50 \%$ of the children have poorly controlled asthma, even in this selected population, is of great concern.

Poor attendance to the doctor due to poor symptom perception, failure of the physician to adhere to treatment guidelines, insufficient adherence by children and parents and the presence of extremely severe, therapy-resistant disease have all been proposed as possible reasons for suboptimal asthma control $[16,19-21]$. The study was performed in a patients' organisation, whose voluntary nature suggested unusual motivation. Thus, all parents were aware of the disease, $99 \%$ of those with unsatisfactory control were in regular follow-up for asthma, with $50 \%$ receiving specialist care.

Medical treatment options and preventive measures, although better utilised than in unselected population samples, were certainly not exhausted. Using a simple definition of "undertreatment" only a comparatively small proportion of undertreated children was found: $82 \%$ of the group used $\beta_{2}$-agonists and $68 \%$ ICS. This compares favourably to a random sample of Swiss schoolchildren, where only $31 \%$ of the males and $15 \%$ of the females with current wheeze had a bronchodilator [8]. In a recent European study, only $26 \%$ of children with severe persistent asthma had taken ICS in the past 4 weeks [10], while in other population-based surveys, the proportion of children treated with an anti-inflammatory inhaler ranged $26-69 \%[6,9,11,22-24]$.

Quantifying asthma therapy revealed, however, substantial undertreatment in terms of intensity and duration of medication: only the minority of children with poor asthma control were on step 3 or 4 of BTS guidelines, and only $27 \%$ used ICS daily for the past 12 months, while most children had only short courses, a problem which has also been reported from the UK $[23,25]$. Most of the children with poor asthma control could thus be stepped up easily, without incurring a significant risk of side-effects. Inadequate symptom control is unlikely to be substantially explained by severe, therapy-resistant asthma. Doctors and/or parents seem, however, reluctant to step up treatment with increasing clinical severity, as suggested by guidelines. In comparison to the survey of the National Asthma Campaign in the UK, where $13 \%$ of the children with diagnosed asthma were untreated, and $24 \%, 50 \%, 6 \%$ and $6 \%$ were at steps $1,2,3 / 4$ and 5 , respectively, the current authors found fewer children receiving a bronchodilator monotherapy (step 1), more children at steps 3 and 4 , but no children on regular oral corticosteroids (step 5). It is more difficult to assess the proportion of overtreated children, as it is impossible to decide which, if any, of the asymptomatic children on steps 3 or 4 could be stepped down without relapsing. The 12 asymptomatic children ( $2 \%$ of the group), taking $>800 \mu \mathrm{g}$ budesonide (or $>500 \mu \mathrm{g}$ fluticasone) daily for $\geqslant 6$ months in the past year, are, however, likely to be on unnecessary high doses. Many children may also use their inhalers inappropriately, as only $45 \%$ of parents could clearly distinguish the effects of anti-inflammatory inhalers from bronchodilators.

The proportion of children exposed to tobacco smoke and domestic pets was approximately one-half that of random samples of Swiss schoolchildren $[26,27]$. Even after adjusting for paternal and maternal education, age, language, year of survey and 
nationality, the ORs, comparing the group with a representative Swiss general population sample [26, 28], were 0.37 and 0.55 for maternal and paternal smoking and $0.45(0.46)$ for keeping a pet (cat) (all p-values $<0.0001$; Ch. Braun-Fahrländer, Institute for Social and Preventive Medicine, University of Basel, Basel, Switzerland, personnel communication). Although this is clearly a positive finding it still suggests a suboptimal adoption of known risk avoidance measures. In contrast to medication and expensive bed covers, avoidance of smoking and pets was no higher among children with poorly controlled disease than with well-controlled subjects. This supports the previously recognised difficulty of changing behaviour, even in this well-informed, mainly high socioeconomic group.

Other factors which might explain poor asthma control and reluctance to intensify treatment in this group include parental tolerance of symptoms and low adherence to prescribed treatment: $28 \%$ of the families reported poor adherence, partly by deliberate under dosing of prescribed drugs from fear of sideeffects. The true rate of noncompliance is likely to be higher. This problem might be alleviated in future by the introduction of new oral nonsteroidal asthma therapeutics, such as leukotriene receptor antagonists not yet on the Swiss market in 1998. Conversely, many parents tolerated a relatively high degree of asthma symptoms in their children, yet considered asthma control to be excellent. These parents' individual expectations and treatment goals were therefore significantly lower than those proposed in guidelines. Such a discrepancy has been shown in two other studies $[10,29]$ and might be an important clue for explaining poor asthma control. It could be interpreted either as an unconscious adaptation of lifestyle in children with chronic asthma, with avoidance of triggers such as strenuous exercise, or else a trade-off between benefits and real or anticipated adverse treatment effects, such as reluctance to use regular medication or fear of side-effects. Patients might therefore willingly accept a residual level of symptoms before they initiate or increase medical treatment. The current authors found a significant association between parental expectations and adherence with inhalation regimens, suggesting a vicious circle of dissatisfaction and nonadherence, which might be very important in clinical practice. Higher maternal education and family size were also independently positively associated with parental dissatisfaction.

Overall asthma control as well as frequency and severity of single symptoms (with the exception of sports limitations) were significantly poorer in younger children. Asthma treatment also differed by age, with significantly lower treatment intensity (BTS step) but more use of antibiotics in 4-6-yr olds compared to all other age groups. Even after adjusting for these differences in treatment, asthma control remained significantly lower in younger age groups. This is in keeping with epidemiological data from general population samples [7, 28] and with hospital statistics, which consistently show higher morbidity in younger children. Consequences include reduced quality of life for these children and their families (disturbed sleep, school absences, limitation of playing and family activities) and an unnecessary burden on health services resources, as preschool children and young schoolchildren are responsible for the large majority of emergency visits and hospitalisations.

Due to the cross-sectional nature of the study and the lack of physiological measurements, the reasons cannot conclusively be identified for these age-related differences in asthma control. Alternative/additional factors might contribute: clinical severity of asthma might be higher in younger children, perhaps partly due to higher frequency of symptomatic viral infections or to different airway morphology and physiology. Independent of severity, there seems more reluctance by doctors and/or parents to step up treatment in young children, perhaps due to uncertainties concerning long-term effects of inhaled steroids in this age group. Technical difficulties with inhalation therapy are also likely to be more common in younger children, although few problems were reported by parents. Finally, a larger proportion of 4-6-yr olds might represent certain phenotypes of wheezing illness, which by nature do not respond well to classical asthma treatment (such as viral induced wheeze).

In contrast to age, social class and sex did not influence control and treatment of asthma in this sample. This is in contrast with earlier epidemiological data which suggested significant undertreatment of asthma in Swiss female children compared to male children [8]. The most likely explanation for the discrepancy is a sampling bias with respect to sex: families with an asthmatic male child were, in all age groups, twice as likely to join the parents association, compared to parents of an asthmatic female child. This suggests an important sex bias in disease management by parents. Those families that did join, however, treated their child's asthma similarly regardless of sex.

Results of a survey of a parents' organisation are not representative for the whole population of asthmatic children, but provide complementary information. Interestingly however, frequency and severity of asthma symptoms in the group were not different from unselected samples of schoolchildren. Using identical inclusion criteria (age 7-16 yrs, current wheeze), the severity distribution within the SEAAK population was identical to random samples of Australian and Swiss schoolchildren [7, 13]. The study group differed, however, from a random population in that it was composed of highly motivated native Swiss with a high level of education who had actively tried to improve their knowledge by joining a patients organisation. The proportion of children in specialist care $(42 \%)$ was above the national average [30]. The results are therefore likely to represent the tip of an iceberg; asthma control and management in Switzerland is probably much worse than the present study suggests. Conversely, only a patients organisation with a special interest allows the assessment of control and treatment of asthma in a one-step postal survey with a high response rate, in spite of a very complex questionnaire. In a general population, a similar assessment would only be feasible using an 
expensive two-step design with interviews that might in turn reduce the response rate. In fact, the recent survey of the National Asthma Campaign in the UK, which was based on a random population sample, had a combined response rate of $13 \%(41 \%$ in stage 1 and $33 \%$ in stage 2) and was therefore also not very representative of the general population [11].

An unsolved problem in cross-sectional surveys is the difficulty of distinguishing asthma control from the underlying level of asthma severity. While several authors have drawn attention to the fact that symptom-based severity scores used [13] are confounded by treatment, the alternative solution proposed, of classifying asthma severity by the level of treatment necessary to obtain complete control [19], cannot be applied in population-based studies where the majority of patients are not well controlled, as the study has confirmed. The development and validation of a complex measure of severity (taking into account both symptoms and treatment) [31] for children might in future facilitate international comparisons.

Could the age-related differences be explained by sampling or reporting bias? One might hypothesise that families are more likely to join a parent's organisation if the child's symptoms are poorly controlled or if they are unsatisfied with their doctor. With time, asthma being a disease of fluctuating severity, the children are likely to improve as well as get older. This "regression to the mean" could in fact explain some of the age-dependency of the results reported here. However, hospitalisation statistics and random population surveys also consistently show a higher symptom frequency and severity and poorer asthma control in younger age-groups [7, 28]; it is therefore very unlikely that the current results are explained solely by sampling bias. Another possibility is that parental reporting may be less reliable in older children. This problem was, at least partly, compensated in the present survey by the increasing proportion of older children participating in questionnaire completion.

Important clinical implications of the study include the necessity to pay more attention to younger agegroups including efforts to define precisely the clinical phenotype and to choose appropriate treatment strategies; to make more frequent clinical appointments and to regularly check inhalation technique; and not to refrain from stepping up treatment when justified. Another important suggestion of this study is that a vicious circle may exist between parental dissatisfaction and low compliance, and a discrepancy between goals of parents and those outlined in official guidelines. Parents and children should therefore be included more actively into disease management, with the aim to discuss and harmonise treatment goals and expectations between families and physicians, and to discuss in detail the trade-off between benefits and disadvantages of therapy. Future guidelines might also need to distinguish treatment regimens for different phenotypes of wheezing illness.

The results from this study need confirmation in a representative population sample, ideally using a longitudinal design that can discriminate between severity and control of asthma. The development of a valid compound measure of asthma severity that could take into account both symptomatology and current treatment would be extremely helpful. Future research on, and efforts to improve asthma control should always include young children in whom the need seems to be greatest.

Acknowledgements. The authors would like to thank all the parents who were willing to fill out the extensive questionnaire so carefully. They are also very grateful to L. Borer from MSD Switzerland for the very generous financial support, to $\mathrm{M}$. Weber and E. Müller from the Swiss Association of Parents of Asthmatic and Allergic Children for the excellent cooperation and to M. Silverman, C.D. Butler and $\mathrm{K}$. Ismail for reading and commenting on earlier drafts of the paper.

\section{References}

1. Szucs TD, Anderhub H, Rutishauser M. The economic burden of asthma: direct and indirect costs in Switzerland. Eur Respir J 1999; 13: 281-286.

2. Global Initiative for Asthma (GINA). Global strategy for asthma management and prevention. NIH publication No.02-3659. Washington, National Institutes of Health, National Heart, Lung and Blood Institute, February 2002.

3. British Thoracic Society. The British guidelines on asthma management: 1995 review and position statement. Thorax 1997; 52: S1-S21.

4. Anon. Asthma in infants, children and adolescents: consensus statement (Asthma bronchiale bei Säuglingen, Kindern und Jugendlichen). Paediatrica 1999; 10: 46-51

5. Kaur B, Anderson HR, Austin J, et al. Prevalence of asthma symptoms, diagnosis, and treatment in 12-14 year old children across Great Britain (international study of asthma and allergies in childhood, ISAAC UK). BMJ 1998; 316: 118-124.

6. Paterson NAM, Peat JK, Mellis CM, Xuan W, Woolcock AJ. Accuracy of asthma treatment in schoolchildren in NSW, Australia. Eur Respir J 1997; 10: 658-664.

7. Sennhauser FH, Kuhni CE. Prevalence of respiratory symptoms in Swiss children: is bronchial asthma really more prevalent in boys? Ped Pulmonol 1995; 19: 161-166.

8. Kuhni CE, Sennhauser FH. The Yentl syndrome in childhood asthma: risk factors for undertreatment in Swiss children. Ped Pulmonol 1995; 19: 156-160.

9. Halterman JS, Aligne CA, Auinger P, McBride JT, Szilagyi PG. Inadequate therapy for asthma among children in the united states. Pediatrics 2000; 105: 272-276.

10. Rabe KF, Vermeire PA, Soriano JB, Maier WC. Clinical management of asthma in 1999: the Asthma Insights and Reality in Europe (AIRE) study. Eur Respir J 2000; 16: 802-807.

11. Strachan DP. Defining unmet need: relationship between asthma symptoms, asthma-related disability and level of treatment in a nationwide interview survey. Asthma J 2000; 5: 137-140.

12. Asher MI, Keil U, Anderson HR, et al. International 
Study of Asthma and Allergies in Childhood (ISAAC): rationale and methods. Eur Respir J 1995; 8: 483-491.

13. Rosier MJ, Bishop J, Nolan T, Robertson CF, Carlin JB, Phelan PD. Measurement of functional severity of asthma in children. Am J Respir Crit Care Med 1994; 149: 1434-1441.

14. Braun Fahrlander C, Vuille JC, Sennhauser FH, et al. Respiratory health and long-term exposure to air pollutants in Swiss schoolchildren. SCARPOL Team. Swiss Study on Childhood Allergy and Respiratory Symptoms with Respect to Air Pollution, Climate and Pollen. Am J Respir Crit Care Med 1997; 155: 1042-1049.

15. Usherwood TP, Scrimgeour A, Barber JH. Questionnaire to measure perceived symptoms and disability in asthma. Arch Dis Child 1990; 65: 779-781.

16. Legorreta AP, Christian-Herman J, O'Connor RD, Hasan MM, Evans R, Leung KM. Compliance with national asthma management guidelines and specialty care: a health maintenance organization experience. Arch Intern Med 1998; 158: 457-464.

17. Janson C, Chinn S, Jarvis D, Burney P. Physiciandiagnosed asthma and drug utilization in the European Community Respiratory Health Survey. Eur Respir J 1997; 10: 1795-1802.

18. Maier WC, Arrighi HM, Morray B, Llewllyn C, Redding GJ. The impact of asthma and asthma-like illness in Seattle school children. $J$ Clin Epidemiol 1998; 51: 557-568.

19. Cockcroft DW, Swystun VA. Asthma control versus asthma severity. J Allergy Clin Immunol 1996; 98: 1016-1018.

20. van Schayck CP, van Der Heijden FM, van Den Boom G, Tirimanna PR, van Herwaarden CL. Underdiagnosis of asthma: is the doctor or the patient to blame? The DIMCA project. Thorax 2000; 55: $562-565$.

21. Goodman DC, Lozano P, Stukel TA, Chang C, Hecht J. Has asthma medication use in children become more frequent, more appropriate, or both? Pediatrics 1999; 104: 187-194.
22. Comino EJ, Mitchell CA, Bauman A, et al. Asthma management in eastern Australia, 1990 and 1993. Med J Aust 1996; 164: 403-406.

23. Warner JO. Review of prescribed treatment for children with asthma in 1990. BMJ 1995; 311: 663-666.

24. Powell CV, Primhak RA. Asthma treatment, perceived respiratory disability, and morbidity. Arch Dis Child 1995; 72: 209-213.

25. Walsh LJ, Wong CA, Cooper S, Guhan AR, Pringle M, Tattersfield AE. Morbidity from asthma in relation to regular treatment: a community based study. Thorax 1999; 54: 296-300.

26. Hajnal BL, Braun-Fahrlander C, Grize L, et al. Effect of environmental tobacco smoke exposure on respiratory symptoms in children. SCARPOL Team. Swiss Study on Childhood Allergy and Respiratory Symptoms with Respect to Air Pollution, Climate and Pollen. Schweiz Med Wochenschr 1999; 129: 723-730.

27. Sennhauser FH, Guntert BJ. Prevalence of bronchial asthma in childhood in Switzerland: significance of symptoms and diagnosis. Schweiz Med Wochenschr 1992; 122: 189-193.

28. Braun-Fahrlaender C, Grize-Zertuche L, Vuille J. Schlussbericht "SCARPOL" zu Handen des Schweizerischen Nationalfonds (Swiss Study on Childhood Allergy and Respiratory Symptoms with respect to air pollution, climate and pollen). Projekt Nr. 4026033109; Basel/Bern, 1995.

29. Price D. Delivery of asthma care: patients' use of and views on healthcare services, as determined from a nationwide interview survey. Asthma $J$ 2000; 5: 141-143.

30. Szucs TD, Anderhub HP, Rutishauser M. Determinants of health care costs and patterns of care of asthmatic patients in Switzerland. Schweiz Med Wochenschr 2000; 130: 305-313.

31. Liard R, Leynaert B, Zureik M, Beguin FX, Neukirch F. Using Global Initiative for Asthma guidelines to assess asthma severity in populations. Eur Respir $J$ 2000; 16: 615-620. 